\title{
RECENTES AVANÇOS E NECESSIDADES DE PESQUISA EM TETANO*
}

\author{
Walter Tavares**
}

\begin{abstract}
O autor faz uma análise sobre a bacteriologia do Clostridium tetani, citando trabalhos recentes que evidenciam a termo-sensibilidade $e$ a não-fermentaça da glicose como caracter/sticas das cepas toxigências. Esclarece ainda diversos aspectos da patogenia do tétano, deixando várias questōes da mes. ma em aberto e traça um esquema de profilaxia para a doença.
\end{abstract}

\section{INTRODUÇÃO}

Conhecido desde a antigüidade, o tétano sempre despertou o interesse dos cientistas pelos seus aspectos clínicos e epidemiológicos, as características de seu agente etiolóqico, sua alta gravidade, as dificuldades terapêuticas e o elevado custo do tratamento. $O$ interesse pela doença, a necessidade de divulgação de novos conhecimentos e de debate sobre seus vários aspectos, fizeram com que nos últimos anos pesquisadores de todo o mundo se reunissem, a cada 4 anos, em conferências sobre o tétano, a terceira das quais ocorreu em 1970, em São Paulo, e a última em Dacar, Senegal, em 1975.

A soma de informações trazidas por trabaIhos isolados e apresentados nas Conferências Internacionais sobre o tétano faz com que esta doença seja das mais conhecidas em seus aspectos etiológicos, clínicos, epidemiológicos, terapêuticos e profiláticos. É este conhecimento que permite a afirmação de ser o tétano uma das poucas doenças infecciosas erradicáveis na Terra. Como afirma Furste, o tétano deveria ser somente uma recordação. . ., mas não é, principalmente nos países de menor desenvolvimento, onde constitui uma das principais causas de morte.

Sendo o Brasil um dos países com maiores índices de morbidade e mortalidade pelo tétano, está perfeitamente justificado a inclusão do tema no Congresso da Sociedade Brasileira de Medicina Tropical, realizado no Rio de Janeiro em 1975, onde se discutiram os problemas prioritários em Saúde Pública. Assim, procuramos apresentar os recentes avanços $e$ as necessidades de pesquisa sobre a doença, subdividindo o tema nos seguintes ítens:

\section{Etiologia}

Desde os trabalhos originais de Nicolaier. Rosenbach, Kitasato, Faber e Tizzoni e Catani reconhece-se que o tétano é causado por exotoxinas elaboradas pelo Clostridium tetani, bacilo Gram-positivo, anaeróbio estrito, não fermentador de açúcares, produtor de esporos termo-resistentes. Estudos recentes demonstram que estes aspectos clássicos do bacilo tetánico variam com a amostra em estudo, havendo em a natureza cepas não produtoras de

\footnotetext{
* - Trabalho apresentado no Painel sobre Tétanorealizado durante o XI Congresso da Sociedade Brasileira de Medicina Tropical, no Rio de Janeiro, em 1975

* - Prof. Adjunto do Departamento de Medicina Clínica (Lisciplina de Doencas infecciosas e Parasitárias), Faculdade de Medicina da U.F.F
} 
toxina, amostras fermentadoras de glicose e cepas cujos esporos são sensíveis à ação da temperatura. Os trabalhos de Sanada e Nishida e oútros autores têm revelado que os esporos das cepas toxinogênicas são mais sensíveis ao calor, sendo inativadas a $80^{\circ} \mathrm{C}$ ou $100^{\circ} \mathrm{C}$ por 10 a 30 minutos. Sanada e Nishida relatam, ainda, que as amostras fermentadoras da gligose em geral não são toxinogênicas. Estes achados revestem-se de importância, visto que a não fermentação de açúcares era um dos dados considerados na caracterização do $C$. tetani, bem como o aquecimento do material suspeito era utilizado como técnica de isolamento do germe em cultura pura.

Outros avanços relacionados à bacteriologia do tétano dizem respeito à caracterização de um terceiro componente da toxina tetânica, a neurotoxina não espasmogênica, da qual falaremos adiante; a descoberta de novos meios de cultura e técnicas de obtenção da toxina tetânica; a individualização de formas $L$ do bacilo. No entanto, alguns elementos ligados à biologia do germe necessitam de ser investigados. Neste sentido sugerimos:

a) Estudos sobre a adaptação do C. tetani à vida aeróbia e sua reversão ao estado anaeróbio, conforme sugestão de D'Antona e outros autores italianos.

b) Estudos sobre as necessidades nutricionais do $C$. tetani e a importância que elementos químicos exercem sobre a produção da toxina, tomando por base os trabalhos de Feeney, Mueller e Miller mostrando ser o ferro um elemento essencial ao crescimento e toxinogênese do bacilo.

c) Estudos sobre a influência de germes associados na produção da toxina tetânica, tomando por base os antigos trabalhos de Tulloch, Ninni e Tenbroeck e Bauer que referiam inibição da toxinogênese quando o $C$. tetani encontra-se em cultura mista. Dentro desta mesma linha, e ao contrário dos autores anteriores, Regamey e Adamson referem uma ação sinérgica, na produção da toxina tetânica, com a presença de outros germes.

d) Estudos da importância das formas $L$ do bacilo tetânico, induzidas pela penicilina, nas recaídas do tétano.

\section{Patogenia}

A patogenia do tétano foi recentemente esclarecida em numerosos aspectos, graças aos trabalhos de Wrigth, Fedinec, Kryzhanovsky,
Van Heyningen e Mellamby, Feigen e col. e Kerr e col., entre muitos outros autores. De uma maneira resumida, a patogenia do tétano é assim compreendida:

O C. tetani produz três tipos de toxinas:tetanospasmina, neurotoxina não espasmogênica e tetanolisina, das quais a última não parece exercer maior importância. Após a penetração nos tecidos, o bacilo tetânico pode permanecer num estado latente (esporulado) por algumas horas ou dias, na dependência das condições de anaerobiose e fagocitose local. Quando presente um baixo potencial de oxiredução, a germinação ocorre em cerca de 6 horas e a forma vegetativa logo inicia a produção da toxina, a qual atinge nivel máximo em torno da 40a hora. Uma vez produzida, a tetanospasmina atinge os centros medulares e bulbares por via nervosa, transportada pelos li quidos presentes no epinêurio e perinêurio em um movimento centrípeto devido a um gradiente de pressão gerado pelos músculos em contração. Tal absorção neural se dá não somente nos nervos da região onde se injeta ou é liberada a toxina, mas também pelas ter. minações de outros nervos, onde chega transportada pelo sangue e linfa. Este mecanismo explicaria a intoxicação precoce de nervos motores cranianos, responsáveis pelo trismo, facies tetânico e rigidez de nuca, devido à rápida absorção da toxina tetânica pelo menor comprimento e maior susceptibilidade de tais nervos. A tetanospasmina é rapidamente absorvida, chegando ao S.N.C. em horas 18 a 9 horas em ratos), indo agir na sinapse dos neurônios motores inferiores com os interneurônios inibidores de Renshaw, desta maneira inibindo a ação inibidora destes sobre os primeiros. Com isto, os neurônios motores inferiores permanecem estimulados por impulsos que vêm do cérebro e regiões sensoriais. Na ausência de inibição reflexa entre músculos agonistas e antagonistas, toda a musculatura permanece estimulada, contraindo-se. Ao nível molecular, está estabelecido que os receptores da membrana pré-sináptica ao qual a toxina se fixa são gangliosídeos, formados sobretudo pelo ácido $\mathrm{N}$-acẹtil-neuramínico, sendo a fixação favorecida por cerebrosídeos da célula. O mecanismo íntimo de ação da toxina consiste em bloquear a liberação do mediador neuro-químico, que se supõe ser a glicina.

Além da sua ação central, a tetanospasmina exerce uma ação periférica ao nível da placa motora, provocando uma inibição da transmissão neuro-muscular. Sua ação é exercida na 
membrana pré-sináptica, impedindo a liberação do mediador químico, que é a acetilcolina. Mais recentemente, Feigen e col. demonstraram um outro efeito na placa motora, devido ao componente não espasmogênico da toxina tetânica, o qual diminui o potencial da placa.

Como se observa, na complexa patogenia do tétano dois tipos de fenômenos ocorrem: uma estimulação muscular permanente causada pela liberação do neurônio motor inferior e pela diminuição do potencial da placa motora: e um distúrbio na transmissão neuro-muscular levando à flacidez, a qual não é observada na maioria dos casos pela maior intensidade do efeito anterior.

Além destes efeitos neurológicos, Kerr e col. admitem que a toxina tetânica tenha ação sobre o sistema nervoso autônomo provocando uma hiperatividade do simpático, manifestada pela taquicardia, sudorese, hipertermia e hipertensão arterial. Este aspecto da patogenia do tétano necessita de maiores esclarecimentos, bem como outras questões que permanecem em aberto:

a) Qual o destino biológico da toxina após a fixação no receptor? Ou seja, como se dá a metabolização das toxinas?

b) Que alteração biológicas ocorrem nas células nervosas intoxicadas?

c) Qual o papel dos nervos sensitivos na absorção da toxina, uma vez que experimentalmente a toxina pode ser detectada em tais nervos?

d) Porque a infecção tetânica num animal se manifesta por sinais localizados no membro onde se injetou a toxina, enquanto no homem o primeiro sinal da doença é o trismo e a rigidez de nuca, qualquer que seja o foco de infeccão?

e) Qual a importância da via hematogênica na chegada da toxina ao sistema nervoso?

f) Qual a ação da toxina sobre os centros vegetativos, músculos e outros órgãos?

g) Qual a possibilidade do esporo tetânico permanecer num foco cicatrizado por meses e anos, explicando casos de tétano com longos períodos de incubação?

\section{Imunidade}

É clássica a noção de que o tétano não provoca-imunidade, tendo por base os relatos de recidivas da doença e a ausência de anticorpos circulantes em pacientes recuperados. Esta ausência de imunidade tem sido explicada pela alta potência da toxina tetânica, de tal forma que quantidades mínimas são capazes de causar a doença e até matar o homem, mas são insuficientes para a estimulação do sistema imunitário (Warter). Uma outra explicação é fornecida recentemente por Hiotakis e col. que demonstram uma ação linfodepressora da toxina tetânica sobre o sistema linfático. Este e outros pontos ainda não definitivamente solucionados necessitam de maiores estudos.

Um aspecto, de confirmação recente, diz respeito à imunidade naturalmente adquirida contra o tétano. Antigos trabalhos de Tenbroeck e col. admitiam a aquisição de proteção antitóxica pela estimulação antigênica do C. tetani presente no tubo digestivo. Muito embora sabendo-se que a toxina tetânica é inativada pelos sucos digestivos e não é absorvida pela mucosa intestinal, sempre haveria a possibilidade de infecções subclínicas na mucosa digestiva. Em recentes trabalhos, Veronesi e col. encontraram títulos de antitoxinas em individuos vivendo em área de alta contaminação do solo pelo bacilo tetânico, atribuindo tal imunidade natural a infecções sub-clínicas.

A imunidade contra o tétano é facilmente adquirida pela injeção do toxóide tetânico, especialmente quando absorvido em adjuvantes. Neste sentido, vêm os pesquisadores se dedicando à possibilidade de imunização com - uso de uma única dose de toxóides altamente concentrados e contendo diferentes tipos de adjuvantes e, mesmo, a possibilidade de. imunização por via oral ou sob a forma de aerosol.

Podemos, então, sugerir algumas linhas de pesquisa quanto à imunidade do tétano:

a) Qual a importância da depressão linfocitária no não surgimento da imunidade em tetânicos?

b) Estudos no sentido de averiguar se a doença é capaz de despertar uma imunidade básica e que se tornaria manifesta pela injeção de uma só dose da vacina contendo adjuvantes

c) Ampliação dos estudos sobre imunidade naturalmente adquiridas por infecções subclínicas.

d) Ampliação dos estudos com toxóides contendo diferentes adjuvantes.

e) Novos estudos sobre a duração da imunidade após a vacinação e da resposta imunológica com diferentes prazos entre a aplicação das doses de reforço. 


\section{Tratamento}

Basicamente o tratamento do tétano consiste na aplicação da antitoxina, debridamento do foco, sedação, miorrelaxamento, uso de antibióticos e medidas gerais de suporte.

Os principais avanços neste item dizem respeito ao largo uso dos benzodiazepínicos, a utilização da respiração assistida nos casos de maior gravidade e à substituição do soro antitetânico pela gamaglobulina antitetânica de origem humana. Apesar da existência de novos medicamentos e meios de assistência aos tetânicos, a letalidade ainda é elevada. Daí a importância de três novas concepções terapêuticas, que necessitam maiores estudos. A primeira refere-se aos trabalhos de Ildirim, demonstrando que a utilização do soro antitetânico junto com corticóides por via intraraquiana apresenta excelente ação terapêutica. A segunda refere-se ao uso de doses elevadas do toxóide tetânico com a finalidade de deslocar a toxina fixada a assumir seu lugar nos receptores nervosos. Um terceiro aspecto diz respeito ao uso de bloqueadores adrenérgicos no tratamento e profilaxia da hiperatividade do sistema simpático, especialmente nos casos de maior gravidade.

\section{Epidemiologia}

A epidemiologia do tétano tem sido largamente estudada em todo o mundo, sendo afetada por fatores regionais tais como clima, condições sócio-econômicas da população e medidas profiláticas em uso, sendo bastante claro que os fatores sócio-econômico-culturais são da maior importância na ocorrência da doença.

Nos países em desenvolvimento, a epidemiologia do tétano encontra obstáculos ao seu conhecimento, devido à notificação defeituosa dos casos. Este problema também ocorre no Brasil, devendo-se conclamar os médicos e as autoridades de saúde em geral para a notificação, não só do tétano como de outras doenças transmissíveis, a fim de que se possa fazer o diagnóstico da saúde em nosso país.

Cvjetanovic ressalta a necessidade de identificação dos fatores ligados à ocorrência do tétano, no sentido de melhor se proceder ao controle da doença, concentrando-se as medidas profiláticas nos grupos que apresentam maior risco de adquirir a infecção. Fatores como idade, sexo, profissão, hábitos, nível social, assistência à maternidade, relacionam-se à ocorrência da doença.
Dentre os fatores acima mencionados, trabalhos recentes destacam a influência do grau de contaminação do solo pelo $C$. tetani. Neste particular, estudos devem ser realizados para o melhor conhecimento da distribuição do bacilo tetânico e dos fatores que possam intervir nesta distribuição. Assim, em trabalho que realizamos no Rio de Janeiro, verificamos que o bacilo está presente em alto percentual no solo das cidades, o que atribuímos à concentração do germe condicionada pelos fatores de urbanização. Outros aspectos precisam também ser investigados, tais como a relação entre a presença do germe $e$ as condições físicas do solo, o $\mathrm{pH}$, associações com outros microrganismos, o tipo de vegetação etc.

\section{Profilaxia}

A profilaxia do tétano constitui, acreditamos, a parte mais importante de qualquer seminário a respeito da doença. Torna-se imprescindível enfatizar que o tétano é uma das poucas doenças que na atualidade podem ser erradicadas, graças à vacinação da população. É certo que a imunização não é o único meio de controle, pois a melhoria das condições sócio-econômicas e de assistência aos traumatizados e à maternidade também são elementos efetivos para o combate a doença. Mas, sem dúvida, a imunizaçáo antitetânica da população constitui o principal meio para este combate. Tal medida é altamente eficaz e de fácil realização, sendo numerosos os trabalhos demonstrando que, em termos econômicos, a profilaxia ativa é altamente compensadora em relação ao tratamento dos casos do tétano. Estes dados levaram os estudiosos em todo o mundo a solicitar que as autoridades de Saúde Pública estabeleçam em regime prioritário, a vacinação sistemática da população.

Experiências levadas a cabo em vários paí. ses comprovam que a aplicação de 2 doses de toxóide tetânico com adjuvante provoca uma resposta imunitária protetora que é mantida pela aplicação de uma dose de reforço após 1 ano e a seguir a cada 10 anos. Esta necessidade de aplicação de duas doses da vacina constitui um óbice aos programas de controle da doença, levando os pesquisadores a procurar novos tipos de toxóide tetânico capazes de imunizar com uma única dose. Experiências com toxóides altamente concentrados e com diversos adjuvantes têm demonstrado sua eficácia (Veronesi, Rey e col.), outros trabalhos sendo esperados para avaliação de novos tipos de toxóides. 
A respeito do tétano neonatorum, as medidas profiláticas indicadas são os cuidados higiênicos do parto e do coto umbilical e a vacinação da gestante no último trimestre da gestação.

No atendimento ao indivíduo traumatizado, sem imunidade ou com estado imunitário, ignorado, recomenda-se a limpeza cirúrgica adequada da ferida, uso do S.A.T. ou gamaglobulina específica e aplicação da 1 a dose de toxóide tetânico, com instruções para prosseguir a vacinação. Nos indivíduos previamente vacinados, faz-se o curativo e aplica-se somente a dose da vacina (dose de reforço). Antibióticos do grupo das tetracilinas poderão ser usados como uma opção ao S.A.T. e naqueles casos com feridas altamente infectadas. A penicilina benzatina não oferece proteção adequada contra o tétano.

Para finalizar, queremos citar 2 outras medidas profiláticas que poderão ser utilizadas nos pacientes traumatizados sem imunização prévia, após estudos mais apurados. A primeira refere-se ao uso do toxóide tetânico em altas doses, com a finalidade de saturar os receptores nervosos, prevenindo desta forma a fixação da toxina. A segunda diz respeito ao uso, logo após o ferimento, de uma mistura de gangliosídeos e cerebrosídeos, por via parenteral, a fim da toxina ser absorvida pela mistura circulante e; desta forma, ser tornada inofensiva.

\section{SUMMARY}

The authors analysis Clostridium tetani bacteriology, mentioning recent reports which proves the thermic-sensibility and glucose non-fermentation as strain toxigenic characteristic. He still clears up about several aspects from tetanus pathogeny and makes an outline of prophylaxis to the disease.

\section{REFERENNCIAS BIBLIOGRAFICAS}

1. D'ANTONA. Le tetanos. Rev. Imunol. 15: 93, 1951.

2. ECKMAN, L. ed. Principles on Tetanus. Proceed. Intern. Tetanus. bern, Huber, 1967. $577 \mathrm{p}$.

3. FEDINEC, A. A. Studies on the mode of Spread of tetanus toxin. 2nd Intern. Pharmacol. Meeting 9: 125, 1965. Oxford, Pergamon Press.
4. PARSONS, R. L.; HOFMANN, W. W. \& FEIGEN, F. A. Mode of action of tetanus toxin on the neuromuscular junction. Amer. J. Physiol. 210, 84 , 1966.

5. PEEBLES, T. C.; LEVINE, L.; ELRED, M. C. \& EDSALL, G. Tetanus toxoid emergency booster. N. Engl. Med. 280: 575, 1969.

6. TASIAAN, A. \& HUYGEN, F. J. A. Immunization against tetanus. Bull. $W: / H O$ 26: 397, 1962.

7. TAVARES, W. Contaminação do solo do Estado do Rio de Jaeiro pelo $C$. tetani. Tese de Doutorado (U.F.R.) Bol. Ci. Inst. Vital Brasil 2: 6, 1975.

8. TAVARES, W.; SEBA, R. \& COURA, J. R. Contaminação do solo do Estado do Rio de Janeiro pelo $C$. tetani. III Estudo da contaminação de áreas urbanas e rurais. Rev. Inst. Med. Trop. S. Paulo 13: 411, 1971.

9. TENBROECK, C. \& BAUER, J. H. Studies on relation of tetanus bacilli in the digestive tract to tetanus antitoxin in blood. J. Exper. Med. 37: 479, 1923.

10. THIRD. INTERN. CONFER. TETANUS. WHO/PAHO Scientific Fubl. n? 253, 1972.

11. VAN KEYNINGEN, N. W. E. Tetanus. Scientific American 218: 69, 1968.

12. VERONESI, R.: GUIDOLIN, R. \& SANTIAGO, A. M. P. Doxicicline in the prevention os experimental tetanus. Rev. Hosp. Clin. S. Paulo 26: 133, 1971.

13. VERONESI, R.; CECIN, H.; CORREA, A.; TAVARES, J.; MORAES, C. \& NASCIMENTO, O. J. New approaches on tetanus immunization: naturally acquired immunity. Rev. Hosp. Clin. S. Paulo 28: 1973.

14. WALTER, J.; MANTZ, J. D.; TEMPE, J. D. \& OTTENI, J. C. Tetanos recidevant. Presse Med. 75: 1225, 1967.

15. WRIGHT, G.P. Nerve trunks as pathways in infection. Proc. R. Soc. Med. 46: $319,1963$. 